Research Article

\title{
Investigation on Tensile and Flexural properties of Cotton Fiber Reinforced Isophthallic Polyester Composites
}

\author{
S.Sabinesh $^{\dot{A}^{*}}$, C.J.Thomas Renald ${ }^{\dot{A}}$ and S.Sathish ${ }^{\dot{A}}$ \\ ${ }^{\grave{A}}$ Department of Manufacturing Engineering, Sri Ramakrishna Engineering College, Coimbatore, Tamilnadu, India
}

Accepted 14 January 2014, Available online 01 February 2014, Special Issue-2, (February 2014)

\begin{abstract}
Natural fiber reinforced composite materials are one such capable material which replaces the conventional and synthetic materials for the practical applications where there require less weight and energy conservation. Increasing concern about global warming and depleting petroleum reserves have made scientists to focus more on the use of natural fibers such as cotton, bagasse, coir, sisal, jute etc. This has resulted in creation of more awareness about the use of natural fibers based materials mainly composites. This paper, which emphasis the importance of cotton fibers which are extracted from cotton plants, the tensile and flexural properties of the cotton fiber are studied and investigated. The mixed chopped cotton fiber reinforced composite is prepared using isophthallic polyester resin by hand lay-up process and the detailed preparation methodology is presented.
\end{abstract}

Keywords: Natural fibers, Cotton fiber, Polymer matrix composites, Isophthallic polyester composites

\section{Introduction}

Unlike plastics, vegetable fibers are biodegradable, annually renewable, non-carcinogenic and therefore health-friendly. Traditionally, jute and jute-like Mesta are being used for packaging as sacking, hessian, bags and soil savers besides being used as carpet backing, jute scrims, tarpaulins, canvass, tar felts, etc. There are other diversified uses too as technical textiles, geo-textiles, agrotextiles and handicrafts. Other allied vegetable fibers like ramie, sisal, flax, pineapple leaf fiber, coir, etc. are also used in single form or in union with jute. The agronomical factors that contribute to good quality jute fiber are close spacing of crops, reduced nitrogenous fertilizers, intercropping and multiple cropping, application of Azotobacter inoculants to soil, pre-flowering harvesting and canal retting. Post-producing retting and mechanical processing which are the two next most important factors specific to the crop are covered. Microbial activity in aqueous medium helps in eliminating pectinous gums and lignin that bind the fibers. The retting process varies from crop to crop and the same is covered in brief under each crop. All the plant fibers mentioned here are natural cellulosic and multicellular in nature except cotton which is unicellular.

Global market is promptly moving towards the energy conservation and energy reduction process. Generally the natural fibers were frequently used to reduce the weight of the components i.e. the fibers are reinforced with the

*Corresponding author: S.Sabinesh suitable matrix. In the aspect of cost, renewable and biodegradability, the natural plant fibers have plenty of advantages when compared to the synthetic fibers. Several authors carried out their research in the area of natural fibers.

\subsection{Polymer matrix composites}

Polymer matrix composites (PMCs) are comprised of a variety of short or continuous fibers bound together by an organic polymer matrix. Unlike a ceramic matrix composite (CMC), in which the reinforcement is used primarily to improve the fracture toughness, the reinforcement in a PMC provides high strength and stiffness. The PMC is designed so that the mechanical loads to which the structure is subjected in service are supported by the reinforcement. The function of the matrix is to bond the fibers together and to transfer loads between them. Polymer matrix composites are often divided into two categories: reinforced plastics, and "advanced composites". The distinction is based on the level of mechanical properties (usually strength and stiffness); however, there is no unambiguous line separating the two. Reinforced plastics, which are relatively inexpensive, typically consist of polyester resins reinforced with lowstiffness glass fibers.

Advanced composites, which have been in use for only about 15 years, primarily in the aerospace industry, have superior strength and stiffness, are relatively expensive. Advanced composites are the focus of this assessment. Chief among the advantages of PMCs is their light weight 
coupled with high stiffness and strength along the direction of the reinforcement. This combination is the basis of their usefulness in aircraft, automobiles, and other moving structures. Other desirable properties include superior corrosion and fatigue resistance compared to metals. Because the matrix decomposes at high temperatures, however, current PMCs are limited to service temperatures below about $600^{\circ} \mathrm{F}\left(316^{\circ} \mathrm{C}\right)$. Experience over the past 15 years with advanced composite structures in military aircraft indicates that reliable PMC structures can be fabricated. However, their high cost remains a major barrier to more widespread use in commercial applications. Most advanced PMCs today are fabricated by a laborious process called lay-up.

This typically involves placement of sequential layers of polymer-impregnated fiber tapes on a mold surface, followed by heating under pressure to cure the lay-up into an integrated structure. Although automation is beginning to speed up this process, production rates are still too slow to be suitable for high-volume, low-cost industrial applications such as automotive production lines. New fabrication methods that are much faster and cheaper will be required before PMCs can successfully compete with metals in these applications.
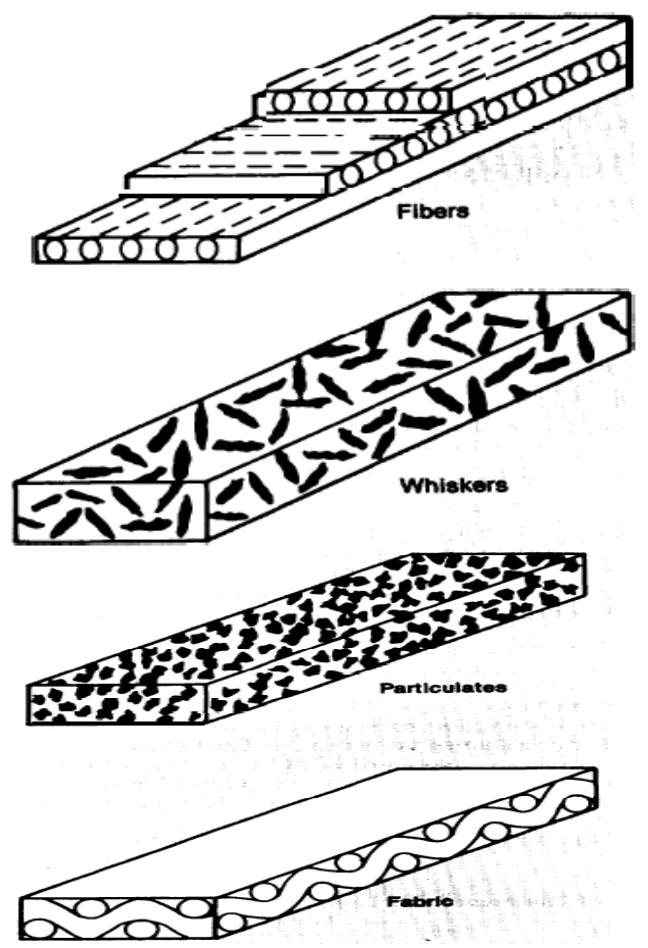

Fig.1 Composite Reinforcement Types (SOURCE: Carl Zweben, General Electric Co)

Unlike a ceramic matrix composite, in which the reinforcement is used primarily to improve the fracture toughness, the reinforcement in a polymer matrix composite provides strength and stiffness that are lacking in the matrix. The composite is designed so that the mechanical loads to which the structure is subjected in service are supported by the reinforcement. The function of the relatively weak matrix is to bond the fibers together and to transfer loads between them, As with CMCs, the reinforcement may consist of particles, whiskers, fibers, or fabrics, as shown in figure 1 .

PMCs are often divided into two categories: Reinforced plastics, and advanced composites, The distinction is based on the level of mechanical properties (usually strength and stiffness); however, there is no unambiguous line separating the two. Reinforced plastics, which are relatively inexpensive, typically consist of polyester resins reinforced with low-stiffness glass fibers (E-glass). They have been in use for 30 to 40 years in applications such as boat hulls, corrugated sheet, pipe, automotive panels, and sporting goods.

Advanced composites, which have been in use for only about 15 years, primarily in the aerospace industry, consist of fiber and matrix combinations that yield superior strength and stiffness. They are relatively expensive and typically contain a large percentage of high-performance continuous fibers, such as high-stiffness glass (S-glass), graphite, aramid, or other organic fibers. This assessment primarily focuses on market opportunities for advanced composites. Less than 2 percent of the material used in the reinforced plastics/PMCs industry goes into advanced composites for use in high-technology applications such as aircraft and aerospace.

\subsection{Natural fiber composites}

Natural fiber composites mostly consists fibers of jute, cotton, hemp and non-conventional fibers such as coir and many empty fruit bunches. Natural fiber thermoplastic composites are attractive as they are cheaper, stiffer, paintable, rot-resistant and also can be given the look of wood in addition to all this they have more life- cycle. Natural fiber composites are attractive to industry because of their low density and ecological advantages over conventional composites Natural fibers are lingo cellulosic in nature. These composites are gaining importance due to their non-carcinogenic and bio-degradable nature. Natural fiber composites are very cost effective material especially in building and construction purpose packaging, automobile and railway coach interiors and storage devices. These can be potential candidates for replacement of high cost glass fiber for low load bearing applications.

A better understanding of the chemical composition and surface adhesive bonding of natural fiber is necessary for developing natural fiber-reinforced composites. The components of natural fibers include cellulose, hemicelluloses, lignin, pectin, waxes and water soluble substances. The composition may differ with the growing condition and test methods even for the same kind of fiber. Cellulose is a semi crystalline polysaccharide made up of D-glucopyranose units linked together by $\beta-(1-4)$ glucosidic bonds and the large amount of hydroxyl group in cellulose gives natural fiber hydrophilic properties when used to reinforce hydrophobic matrix; the result is a very poor interface and poor resistance to moisture absorption Hemicellulose is strongly bound to cellulose fibrils presumably by hydrogen bonds. Hemicellulosic polymers are branched, fully amorphous and have a significantly lower molecular weight than cellulose. Because of its open 
structure containing many hydroxyl and acetyl groups, hemicellulose is partly soluble in water and hygroscopic . Lignins are amorphous, highly complex, mainly aromatic, polymers of phenyl propane units but have the least water sorption of the natural fiber components. Because of the low interfacial properties between fiber and polymer matrix often reduce their potential as reinforcing agents due to the hydrophilic nature of natural fibers, chemical modifications are considered to optimize the interface of fibers. Chemicals may activate hydroxyl groups or introduce new moieties that can effectively interlock with the matrix. The development of a definitive theory for the mechanism of bonding by chemicals in composites is a complex problem. Generally, chemical coupling agents are molecules possessing two functions. The first function is to react with hydroxyl group of cellulose and the second is to react with functional groups of the matrix.

Global market is promptly moving towards the energy conservation and energy reduction process. Generally the natural fibers were frequently used to reduce the weight of the components i.e. the fibers are reinforced with the suitable matrix. In the aspect of cost, renewable and biodegradability, the natural plant fibers have plenty of advantages when compared to the synthetic fibers. Several authors carried out their research in the area of natural fibers.

Athijayamania et al. extracted the roselle and sisal fibers by simple manual water treatment process. The variation of mechanical properties such as tensile, flexural, and impact strengths of roselle and sisal fibers hybrid polyester composite at dry and wet conditions were studied.

Sathish kumar extracted the snake grass natural fiber and given the Tensile and flexural properties of snake grass natural fiber reinforced isophthallic polyester composites The present paper, which emphasis the importance of the newly identified snake grass fibers which are extracted from snake grass plants by manual process. In this paper, the tensile properties of the snake grass fiber are studied and compared with the traditionally available other natural fibers. The mixed chopped snake grass fiber reinforced composite is prepared by using the isophthallic polyester resin and the detailed preparation methodology is presented.

Alomayri detailed the Characterisation of cotton fiberreinforced geopolymer composites, this paper describes the physical, mechanical and fracture behavior of fly-ash based geopolymer reinforced with cotton fibers (0.3-1.0 wt \%). Results show that the appropriate addition of cotton fibers can improve the mechanical properties of geopolymer composites. In particular, the flexural strength and the fracture toughness increase at an optimum fiber content of $0.5 \mathrm{wt} \%$. However, as the fiber content increases, the density of geopolymer composites decreases due to an increase in porosity and tendency of fiber agglomeration.

Alomayri and Low given the Synthesis and characterization of mechanical properties in cotton fiberreinforced geopolymer composites and described the synthesis of cotton fiber-reinforced geopolymer composites and the characterization of their mechanical properties.

Bakare et al. studied the mechanical properties of the sisal fiber rubber seed oil polyurethane composite, with and with-out water treatment process. Rubber seed oil polyurethane resin synthesized using rubber seed monoglyceride derived from glycerolysis of the oil was used as matrix in the composite samples. Rubber seed oilbased polyurethane composite reinforced with unidirectional sisal fibers were prepared and characterized. Mathur prepared the sisal, jute and coir fiber reinforced composites with unsaturated polyester/epoxy resin. The potential of sisal and jute fibers as reinforcements have been systematically investigated to overcome their welldefined problems of moisture absorption. The performance of polymer composites made from these natural fibers and unsaturated polyester/epoxy resin was evaluated under various humidity, hygrothermal and weathering conditions.

Shinji et al. also investigated the mechanical properties of kenaf natural fibers. The unidirectional biodegradable composite materials were made from kenaf fibers and an emulsion-type PLA resin. The biodegradability of kenaf/PLA composites was examined for four weeks using a garbage-processing machine. Experimental results showed that the weight of composites decreased $38 \%$ after four weeks of composting.

Igor et al. investigated the importance of phormium (flax fiber)/epoxy laminated composite with short fiber and long fiber. Various chemical compositions of the fibers were compared with the other natural fibers Two series of laminates were produced using the same reinforcement content (20 wt.\%), arranged either as short fibers or quasi-unidirectional ones. thermal behavior of both untreated phormium fibers and composites has been studied by thermogravimetric analysis (TGA), revealing the thermal stability of composites to be higher than for phormium fibers and epoxy matrix alone.

Sapuan. Investigated the tensile and flexural (threepoint bending) tests were carried out using natural fiber with composite materials (Musaceae/epoxy). Three samples prepared from woven banana fiber composites of different geometries were used in this research. From the results obtained, it was found that the maximum value of stress in $\mathrm{x}$-direction is $14.14 \mathrm{MN} / \mathrm{m} 2$, meanwhile the maximum value of stress in y-direction is $3.398 \mathrm{MN} / \mathrm{m} 2$. For the Young_s modulus, the value of $0.976 \mathrm{GN} / \mathrm{m} 2$ in $\mathrm{x}$ direction and $0.863 \mathrm{GN} / \mathrm{m} 2$ in y-direction were computed.

Venkateshwaran also worked on the natural fiber reinforced composite. The tensile strength and modulus of the longitudinal and random orientated fiber composite were studied and compared. It is found that $1 \% \mathrm{NaOH}$ treated fiber reinforced composites behaves superiorly than other treated and untreated fiber composite. Further, SEM image analysis also shows the effect of alkali concentration over the fiber surfaces which leads to improving the mechanical properties of the composite.

Hoi-yan Cheung et al. briefly investigated given the Natural fiber-reinforced composites for bioengineering and environmental engineering applications. Also given the use of natural fiber mixed with biodegradable and 
bioresorbable polymers which can produce joints and bone fixtures to alleviate pain for patients. In this paper, a comprehensive review on different kinds of natural fiber composites is given. Their potential in future development of different kinds of engineering and domestic products are also discussed in detail.

\subsection{Extraction of cotton fiber}

After bolls of cotton are picked by hand or by mechanical picker-harvester from matured plants, they are ginned with the help of either saw or roller gins to separate the 15$60 \mathrm{~mm}$ discrete fibers from lints. Plant debris and foreign matters are cleaned from ginned cotton, and the clean cotton characteristically of good spinability with aspect ratio of 1300 is processed through a series of machines in the entire spinning lines like opening \& cleaning in blowroom, carding, drawing, roving and spinning.

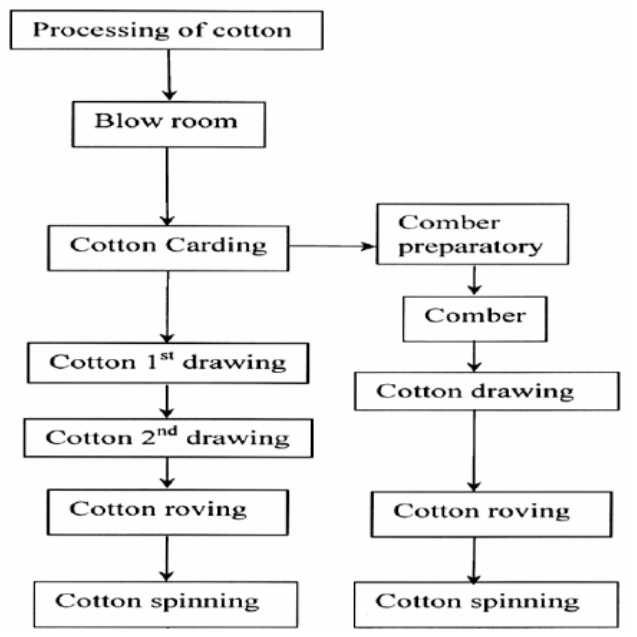

Fig.2 Process flowchart of Cotton fiber

\section{Experiments}

\subsection{Fiber materials}

Cotton fiber (Gossypium Hirsutum) is composed of concentric layers. The cuticle layer on the fiber itself is separable from the fiber and consists of wax and pectin materials. The primary wall, the most peripheral layer of the fiber, is composed of cellulosic crystalline fibrils. The secondary wall of the fiber consists of three distinct layers.

Table 1.Raw cotton components

\begin{tabular}{|l|l|}
\hline $80-90 \%$ & Cellulose \\
\hline $6-8 \%$ & Water \\
\hline $0.5-1 \%$ & Waxes and fats \\
\hline $0-1.5 \%$ & Proteins \\
\hline $4-6 \%$ & Hemicelluloses and pectin's \\
\hline $1-1.8 \%$ & Ash \\
\hline
\end{tabular}

All three layers of the secondary wall include closely packed parallel fibrils with spiral winding of $25-35^{\circ}$ and represent the majority of cellulose within the fiber. The innermost part of cotton fiber- the lumen- is composed of the remains of the cell contents. Before boll opening, the lumen is filled with liquid containing the cell nucleus and protoplasm. The twists and convolutions of the dried fiber are due to the removal of this liquid. The cross section of the fiber is bean-shaped, swelling almost round when moisture absorption takes place. The overall contents are broken down into the following components.

During scouring (treatment of the fiber with caustic soda), natural waxes and fats in the fiber are saponified and pectin's and other non-cellulose materials are released, so that the impurities can be removed by just rinsing away. After scouring, a bleaching solution (consisting of a stabilized oxidizing agent) interacts with the fiber and the natural color is removed. Bleaching takes place at elevated temperature for a fixed period of time. Mercerization is another process of improving sorption properties of cotton. Cotton fiber is immersed into 18$25 \%$ solution of sodium hydroxide often under tension. The fiber obtains better luster and sorption during mercerization.

After scouring and bleaching, the fiber is $99 \%$ cellulose. Cellulose is a polymer consisting of anhydroglucose units connected with 1,4 oxygen bridges in the beta position. The hydroxyl groups on the cellulose units enable hydrogen bonding between two adjacent polymer chains. The degree of polymerization of cotton is 9,000-15,000. Cellulose shows approximately 66\% crystallinity, which can be determined by X-ray diffraction, infrared spectroscopy and density methods.

Each crystal unit consists of five chains of anhydroglucose units, parallel to the fibril axis. One chain is located at each of the corners of the cell and one runs through the center of the cell. The dimensions of the cell are $\mathrm{a}=$ $0.835 \mathrm{~nm}, \mathrm{~b}=1.03 \mathrm{~nm}$ and $\mathrm{c}=0.79 \mathrm{~nm}$. The angle between ab and $\mathrm{BC}$ planes is $84^{\circ}$ for normal cellulose, i.e., Cellulose I [16]. The current consensus regarding cellulose crystallinity (X-ray diffraction) is that fibers are essentially $100 \%$ crystalline and that very small crystalline units imperfectly packed together cause the observed disorder.

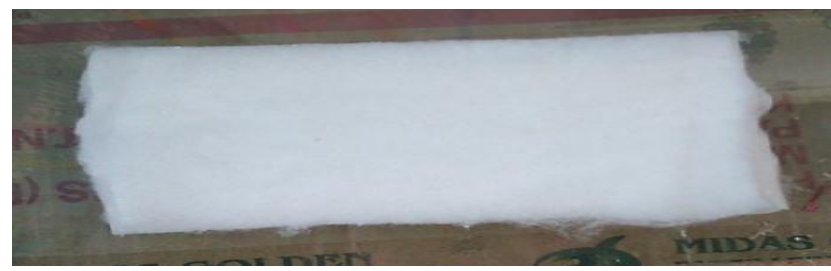

Fig 3. Cotton fiber

Table 2.Properties of Cotton fiber

\begin{tabular}{|l|l|}
\hline Density & $1600 \mathrm{Kg} / \mathrm{m}^{3}$ \\
\hline Specific gravity & 1.54 \\
\hline Tensile strength & $287-597 \mathrm{MPa}$ \\
\hline Tensile modulus & $5.5-12.6$ \\
\hline \% Elongation & $3-10$ \\
\hline
\end{tabular}

The density method used to determine cellulose crystallinity is based on the density gradient column, where two solvents of different densities are partially mixed. Degree of Crystallinity is, then, determined from the density of the sample, while densities of crystalline 
and amorphous cellulose forms are known (1.505 and 1.556 respectively). Orientation of untreated cotton fiber is poor because the crystallites are contained in the micro fibrils of the secondary wall, oriented in the steep spiral $\left(25-30^{\circ}\right)$ to the fiber axis.

\subsection{Polyester resin}

Commercially available isophthallic unsaturated polyester resin is used for the investigation. Accelerator (Methyl Ethyl Ketone Peroxide) and the catalyst (Cobalt Naphthalene) are used to cure the resin. Thermoset isiophthallic polyester resin is one of the economical resins when compare to other resins due to its very low water absorbing capability and excellent bonding tendency as well as mechanical properties. The distinctive properties of the isophthallic polyester resin are shown in Table 3

Table3.Properties of Isophthallic resin

\begin{tabular}{|l|l|l|}
\hline Property & Unit & Range \\
\hline Specific gravity & - & $1.1-1.46$ \\
\hline Density & $\mathrm{kg} / \mathrm{m}^{3}$ & 1125 \\
\hline Tensile strength & $\mathrm{MPa}$ & 18 \\
\hline Tensile modulus & $\mathrm{GPa}$ & $0.8-1.1$ \\
\hline $\begin{array}{l}\text { Compressive } \\
\text { strength }\end{array}$ & $\mathrm{MPa}$ & $90-250$ \\
\hline Flexural strength & $\mathrm{MPa}$ & 30 \\
\hline Flexural modulus & $\mathrm{GPa}$ & $1.2-1.5$ \\
\hline Shrinkage & $\%$ & $0.004-0.008$ \\
\hline
\end{tabular}

\subsection{Preparation of the composite specimen}

The extracted fibers are chopped into random lengths to prepare the composites. The simple hand lay-up technique is adapted to prepare the composite specimen with various volume fractions $\left(\mathrm{V}_{\mathrm{f}}\right)$ like $10 \%, 15 \%, 20 \%, 25 \%$ and $30 \%$ respectively. One percent of catalyst and one percent of accelerator is used to cure the isophthallic polyester resin. Steel dies are designed to prepare the composite specimens. Initially the releasing agent is coated over the male and female section of the die for easy removal of the specimens after the solidification process.

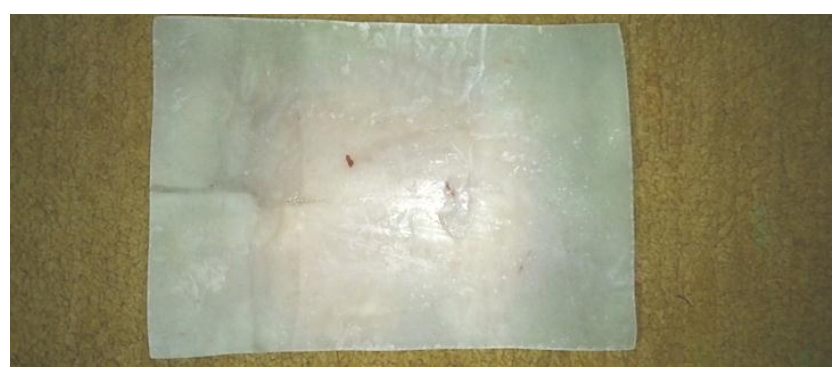

Fig.4 Composite material

The surfaces are then allowed to dry for $15 \mathrm{~min}$, and the fibers are spread over the die. Fiber orientation and uniformity in the composites are maintained by the rolling process using steel rollers to achieve the maximum isotropic material property and almost all the air bubbles are removed by the continuous rolling process. At the time of curing, the closed mould is kept on the hydraulic press and a compressive pressure is applied for $8 \mathrm{~h}$ at atmospheric temperature. Finally the fibers are reinforced with the polyester resin within the mould cavity of dimensions $230 \mathrm{~mm} \times 200 \mathrm{~mm} \times 4 \mathrm{~mm}$ to prepare the required composite plate. After solidification process, the composite plate is then post-cured for one hour in oven.

\subsection{Analysis}

\subsubsection{Tensile testing of a single fiber}

The tensile properties of the long continuous snake grass fiber were measured by a single fiber tensile testing method according to the ASTM D3379-75 standards using the Instron Universal Testing machine. The gauge length of each fiber was taken as $100 \mathrm{~mm}$ and a $1000 \mathrm{~g}$ load cell was used for the testing. The cross head speed of the grippers was $5 \mathrm{~mm} / \mathrm{min}$ and the same speed was used throughout the testing. Twenty-five samples were tested in this work and the average value of the tensile strength; tensile modulus and elongation at the failure/break were obtained. The density of the fiber was evaluated using the meltbertoledoxsz05 balances method.

\subsubsection{Tensile testing of the composite}

Tensile tests were conducted for the composite specimen using the electronic tensometer setup to obtain the tensile properties. The dog-bone specimens of the composites were prepared according to the ASTM D 638 standards. The specimens were machined to a standard size of 165 $\mathrm{mm} \times 13 \mathrm{~mm} \times 4 \mathrm{~mm}$ for a gauge length of $50 \mathrm{~mm}$. For this testing, the load cell of $5 \mathrm{kN}$ was utilized in the tensometer with the same cross head speed of $1 \mathrm{~mm} / \mathrm{min}$. Five identical test specimens were used for each testing. During tensile testing, the specimens were broken in between the gauge length of the specimen and the corresponding image was shown in Fig. 5.

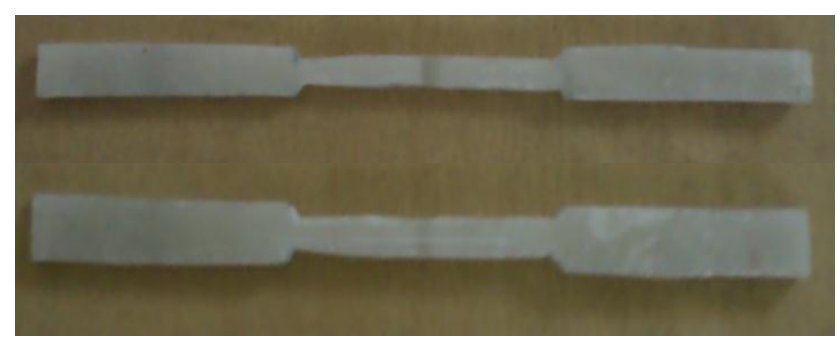

Fig.5 (a) Specimens before tensile test

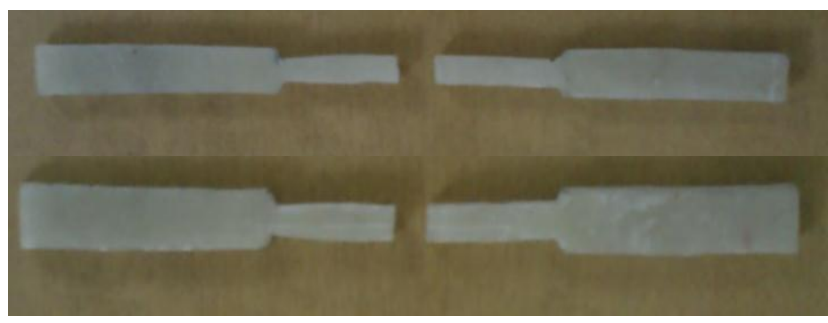

Fig.5 (b) Specimens after tensile test

217 | International Conference on Advances in Mechanical Sciences 2014 


\subsubsection{Flexural testing of the composite}

Three point flexural testing were conducted according to the ASTM D 790 standards [17] using the spring mass testing machine. The specimens were machined for the dimensions of $125 \mathrm{~mm} \times 12 \mathrm{~mm} \times 4 \mathrm{~mm}$. The span to the depth ratio of the specimens was considered as 16:1. For this testing, the load cell of $6 \mathrm{kN}$ was utilized with the cross head speed of $2.5 \mathrm{~mm} / \mathrm{min}$. Five identical test specimens were prepared flexural testing. As similar to the tensile testing, the five identical specimens were broken in between the gauge length and the corresponding image was shown in Fig. 6.

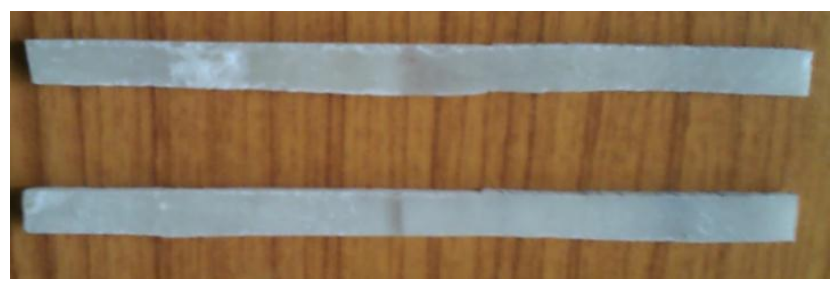

Fig.6(a) Specimens before flexural test

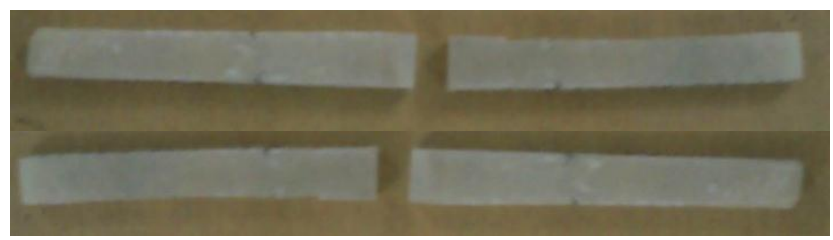

Fig.6 (b) Specimens after flexural test

\section{Result and Discussion}

The raw cotton fibers of gauge length of $100 \mathrm{~mm}$ were taken for the tensile testing. Multiple filaments in the fibers were removed and tested without any surface modification process. The tensile strength of the fiber was obtained by the ratio of average load to the average area for the twenty-five identical samples. Thus the tensile properties are far better to prepare a composite. Density is one of the important parameter for designing any light weighted materials. From table 2 it is clear that cotton can be used for less weight material preparation.

\subsection{Effect of tensile properties of the cotton fiber reinforced composites:}

Table4. Tensile strength for corresponding volume fraction of cotton fiber

\begin{tabular}{|l|l|}
\hline $\begin{array}{l}\text { Volume fraction of cotton } \\
\text { fiber }(\%)\end{array}$ & $\begin{array}{l}\text { Tensile strength } \\
(\mathrm{MPa})\end{array}$ \\
\hline 10 & 23.33 \\
\hline 15 & 25.97 \\
\hline 20 & 33.03 \\
\hline 25 & 39.00 \\
\hline 30 & 19.24 \\
\hline
\end{tabular}

The tensile properties of the chopped cotton fiber reinforced composites are compared with the various fiber volume fractions for random fiber lengths. Fig. 4 shows the variation of tensile strength over the percentage increase in fiber volume fractions.

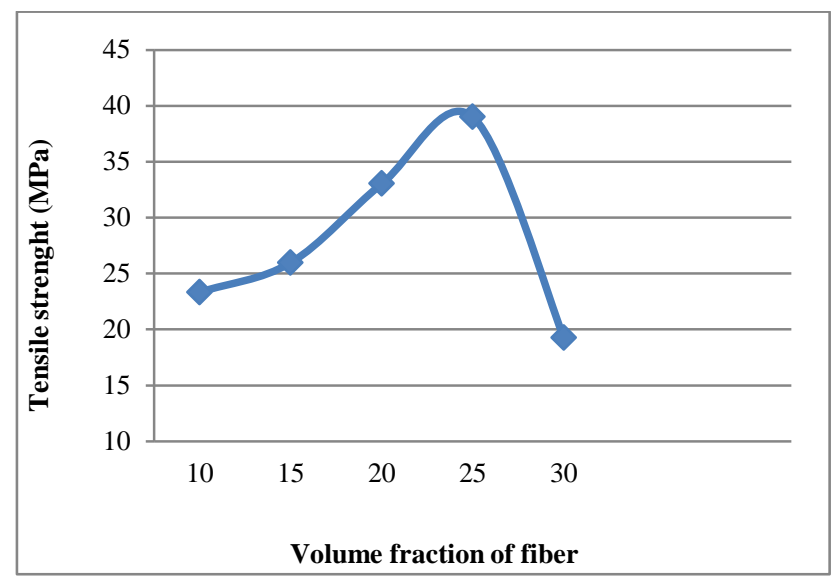

Fig.7 Effect of tensile strength verses volume fraction of cotton fiber

For $10 \% \mathrm{~V}_{\mathrm{f}}$, the fiber accumulation is very less in the composite, so the percentage increase between the maximum and minimum tensile strength for the present case is almost $15.67 \%$. Similar decreasing trend in the tensile strength is visible for other cases up to $25 \% \mathrm{~V}_{\mathrm{f}}$. The percentage increase between the maximum and minimum tensile strength for $15 \% \mathrm{~V}_{\mathrm{f}}$ is $13.03 \%$. This percentage was reduced when compare to $10 \% \mathrm{~V}_{\mathrm{f}}$ is due to the more accumulation of fiber in the composite. Similarly the improvement percentage between the maximum and minimum tensile strength was further reduced to $5.97 \%$ for $20 \% \mathrm{~V}_{\mathrm{f}}$. Maximum tensile strength of $39.00 \mathrm{MPa}$ is obtained for the percentage volume fraction 25 . The percentage improvement between the maximum and minimum tensile strength is high. This percentage is increased when compared to the previous $20 \% \mathrm{~V}_{\mathrm{f}}$. The tensile strength is suddenly drops when the percentage volume fraction is 30 . From the results, it is inferred that the load and stress transfer between the fiber and the matrix is highly reduced due to the less matrix content in composite which is also the main reason for the reduction in tensile strength. The maximum tensile strength of the composite lies in between 25 and $30 \%$ volume fraction of fiber. It is absorbed that the tensile strength of the composite increases with the increase in fiber content. Hence a good load transfer is visible in between the fibers and the matrix. Further increase in the volume fraction highly reduces the tensile strength and load transfers between the fibers and matrix which cannot be a significant one for any applications.

\subsection{Effect of flexural properties of snake grass natural fiber reinforced composites}

The flexural property is one of the important parameter in composites mainly useful to quantify in structural applications. Fig. 8 shows the variations in the flexural strength values over percentage increase in volume fractions. It is observed that the flexural strength values 
are gradually increased up to $20 \% \mathrm{~V}_{\mathrm{f}}$. Beyond $20 \% \mathrm{~V}_{\mathrm{f}}$ of fiber in composite, the flexural strength is suddenly increased. Then the increasing trend suddenly changes and the flexural strength gets drastically reduced when $\mathrm{V}_{\mathrm{f}}$ of fiber in composite is $30 \%$. During the composite preparation, if the fiber content is more than $30 \% \mathrm{~V}_{\mathrm{f}}$, it leads to insufficient filling of matrix into the surrounding fibers and it is one of the main reason for the incomplete composite $.10 \% \mathrm{~V}_{\mathrm{f}}$ composite have the maximum flexural strength of $42.15 \mathrm{MPa}$ and it is increased to $47.93 \mathrm{MPa}$ when the $\% \mathrm{~V}_{\mathrm{f}}$ is 15 and the flexural strength is significantly varied by $5.78 \%$ depends on the fiber content present in the composite. The increasing trend of the flexural strength value continues as like in the previous cases up to the $25 \% \quad \mathrm{~V}_{\mathrm{f}} .25 \% \quad \mathrm{~V}_{\mathrm{f}}$ composite has the maximum flexural strength of 90.23 $\mathrm{MPa}$.The increasing trend suddenly decreases as like in previous cases to 53.86 $\mathrm{MPa}$ when the $\% \mathrm{~V}_{\mathrm{f}}$ of the fiber in composite is 30 . The maximum flexural strength of the composite, in the present case lies at $25 \% \mathrm{~V}_{\mathrm{f}}$. It is also noted that the flexural strength depends upon the fiber content and the fiber length.

Table 5.Flexural strength for corresponding volume fraction of cotton fiber

\begin{tabular}{|l|l|}
\hline $\begin{array}{l}\text { Volume fraction of cotton fiber } \\
(\%)\end{array}$ & $\begin{array}{l}\text { Flexural strength } \\
(\mathrm{MPa})\end{array}$ \\
\hline 10 & 42.15 \\
\hline 15 & 47.93 \\
\hline 20 & 61.40 \\
\hline 25 & 90.23 \\
\hline 30 & 53.86 \\
\hline
\end{tabular}

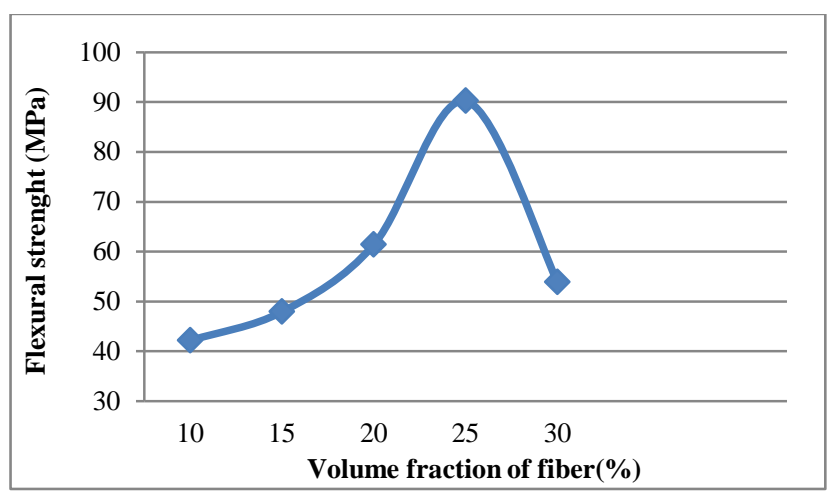

Fig.8 Effect of flexural strength verses volume fraction of cotton fiber

\section{Conclusion}

The tensile and flexural properties of cotton fiber reinforced isophthallic polyester composite are significantly improved with the various fiber volume fractions. It is found that the increase in the fiber volume fraction increases the tensile strengths. The maximum tensile strength and modulus of the chopped fiber isophthallic polyester composite is achieved at $25 \% \mathrm{~V}_{\mathrm{f}}$. The maximum flexural strength of the chopped fiber isophthallic polyester composite is also achieved at $25 \%$ $\mathrm{V}_{\mathrm{f}}$. Overall, it can be concluded that the $25 \%$ volume fraction of the cotton fibers composite have the maximum mechanical properties. The cotton fibers can be extracted with less cost and the composites can be made by simply manual method.

\section{References}

Rowell R.M, Young, Rowell J.K, Paper and composites from agro-based resources, RC Lewis Publishers, Boca Raton RL, (1997) 301-336

Alvarez V.A, Ruscekaite R.A, Vazquez A, Mechanical properties and water absorption behavior of composites made from a biodegradable matrix and alkaline-treated sisal fibers, J. Compos. Mater., 37 (2003) 1575-1588

Frederick T.W, Norman W, Natural fibers plastics and composites, Kluwer Academic Publishers, New York (2004).

Athijayamania A, Thiruchitrambalamb M, Natarajana U, Pazhanivel B. Effect of moisture absorption on the mechanical properties of randomly oriented natural fibers/polyester hybrid composite. Mater Sci Eng 2009;517:344-53.

Sathishkumar T.P. Navaneethakrishnan, P. , Shankar S. Tensile and flexural properties of snake grass natural fiber reinforced isophthallic polyester composites

Alomayri.T, Shaikh, Low I.M,Characterisation of cotton fiberreinforced geopolymer composites. Composites: 2013: 50, 16

Alomayri.T,Low I.M, Synthesis and characterization of mechanical properties in cotton fiber-reinforced geopolymer composites, Journal of Asian Ceramic Societies 2013:130-34.

Bakare IO, Okiemen FE, Pavithran C, Abdul Khalil HPS, Brahma Kumar M. Mechanical and thermal properties of sisal fiber-reinforced rubber seed oilbased polyurethane composites. Mater Des 2010; 3:1167-74.

Mathur V.K,Composite materials from local resources. Constr Build Mater 2006; 20:470-7.

Ochi Shinji. Mechanical properties of kenaf fibers and kenef/PLA composites. Mech Mater 2008; 40:446-52.

De Rosa Igor Maria, Santulli Carlo, Sarasini Fabrizio. Mechanical and thermal characterization of epoxy composites reinforced with random and quasiunidirectional untreated Phormium tenax leaf fibers. Mater Des 2010; 31:2397-405.

Sapuan S.M, Leenie A. , Harimi M., Beng Y.K. Mechanical properties of woven banana fiber reinforced epoxy composites Mater and Des 27 2006:27, 689-93

Venkateshwaran. N, Elaya Perumal. A, Arunsundaranayagam. $\mathrm{D}$, Fiber surface treatment and its effect on mechanical and visco-elastic behavior of banana/epoxy composite Mat and Des 2013: 47, 151:59

Hoi-yan Cheung Natural fiber-reinforced composites for bioengineering and environmental engineering applications Composites:2009:40,655-63

Kelly, A.,The nature of Composite Material, Sci. Amer. Mag. 217 (B) (1967) 161

Mathews, F. L, Rawlings R .D, Engineering Composites 1sI ed. Chapman and Hall, London, (1994)

Jayabal S, Natarajan U. Influence of fiber parameters on tensile, flexural, and impact properties of nonwoven coir-polyester composites. Adv Manuf Technol 2010;70:2969-77. 